\title{
A CASE OF LITHOTOMY,
}

WHERR A

\section{TUMOUR OF THE PROSTATE WAS SUC- CESSFULLY ENUCLEATED;}

\author{
WITH REMARKS ON THE REMOVAL OF SUCH \\ GROWTHS.
}

BY

\author{
REGINALD HARRISON, F.R.C.S., \\ SURGEON TO THE LIVERPOOL ROYAL INFIRMARY, AND LECTURER ON \\ SURGERY AT THE SCHOOL OF MEDICINE.
}

(Received November 19th-Read December 13th, 1881.)

I DESIRE to record this case, not as presenting any novelty in treatment or in operative procedure, but as bearing upon the remedying of prostatic enlargement by means other than those commonly recognised.

If the patient, whose case I am about to relate, had not had a stone in his bladder, he would not in all probability have been cured of his large prostate, or if his stone had been of a size or of a nature which would have permitted of its being removed by any other than a cutting operation, though he might have been relieved of it, he would have been none the more rid of those other urinary troubles which usually attend a large prostate.

To the two-fold accident of having a stone in his 
bladder, and of having it of a size and constitution which did not admit of lithotrity, this patient owes a completeness in recovery which could not otherwise have been attained. Cases such as these, of which mine is not a solitary example, are instructive as suggesting whether it is not possible to apply that portion of their success which is the result of accident, rather than of design, to similar though uncomplicated conditions, where palliative measures, directed towards relieving certain consequences of prostatic hypertrophy, are found to be insufficient. It was remarked by the late Sir William Fergusson, in a communication on this subject to which $I$ shall again refer, "When stone is combined with enlarged prostate who can say from which cause the distress is greatest?" Cases are not infrequent where the symptoms produced by a large prostate are even more urgent than those attending a stone in the bladder.

The following are the particulars of the case I desire, in the first instance, to bring under the notice of the Society :

W. B. H-, a Custom-House officer, æt. 67, was admitted into the Liverpool Royal Infirmary under my care on September 2nd, 1881, having been referred to me by Dr. Samuels. He had been suffering from symptoms of stone for seven years. I sounded him and made out that his bladder contained a large oxalate of lime calculus ; further, that his prostate was enlarged.

On September oth I performed lateral lithotomy; on seizing the stone $I$ found it was so large that $I$ made a bilateral section of the prostate, a course I was prepared for, and which I have successfully adopted on two previous occasions where I had to remove hard stones, weighing over two ounces.

Though this extension of my deep incision gave me additional room for extraction, I recognised that the enlarged prostate still remained an obstacle.

As a portion of the prostate seemed loose and disposed to come away, I enucleated it with my forefinger, and 
slipped it out, when I was able to remove the stone from the bladder without force. There was no bleeding worth mentioning either at the time of or after the operation. The patient made a good recovery and left the Infirmary on November 5th. There was nothing to remark about the temperature during the whole of the treatment.

The tumour remored was about the size of a walnut, and it will be seen that it was almost divided into two portions by the incision into the prostate. In structure it may be described as an adenoma, analogous to what is commonly observed in the breast, and corresponding with the description given of these growths by Sir William Fergusson.

The stone was an unusually large specimen of oxalate of lime, covered with small spines, some of which were broken off by the forceps during extraction. It weighs two ounces and five drachms. By the kindness of my colleague, $\mathrm{Mr}$. Bickersteth, I am enabled to give the particulars of an unpublished case very similar in many respects to that which I have related.

A country gentleman, aged sixty-three, had suffered from symptoms of stone for fifteen years. Mr. Bickersteth, considering that it was a case for lithotomy, performed the lateral operation. Finding as he had anticipated that the stone was large, he extended the deep incision and made a bi-lateral section of the prostate; this enabled him to make out that in addition to the calculus he had a large growth connected with the prostate to deal with. After extracting the stone with the forceps he shelled out with his index finger a mass about the size of a hen's egg, which proved on examination to be an adenoma of the prostate, not a true hypertrophic growth; the stone weighed nearly two ounces and a half. The patient made a good recovery, and to the present date remains perfectly well. The operation was performed on October 21st, 1878.

In 1870 the late Sir William Fergusson drew attention to the subject of lithotomy in connection with 
enlarged prostate, ${ }^{1}$ and narrated a case where, in a patient eighty years of age, after removing the stone by lithotomy he extracted the lower part of the prostate with the finger as readily as if it had been a stone. The patient not only recovered from the operation but never showed any further signs of prostatic irritation.

The paper to which I have referred concludes with the remark: "I have thus ventured to put on record what some of my professional brethren may have hesitated to do from a fear that they may have been guilty in their operations of perpetrating some rough mechanism not in accordance with that nicety of manipulation which is thought so essential in the performance of the master handiwork in surgery-lithotomy."

Mr. Cadge ${ }^{2}$ has reported a case where he removed during a lithotomy, in the forceps between the joint of the blades, three masses which were found to be fibrous outgrowths of the prostate. In commenting upon this case, Mr. Cadge says: "In about two months the wound was perfectly healed; there is incontinence, which may be in a great part due to the removal of the prostatic tumour, but it must be remembered that it also existed before the operation. It has happened to me twice before to remove small fibrous tumours of the prostate gland during the operation of lithotomy and apparently without harm to the patient."

More recently Dr. C. Williams, of Norwich, ${ }^{3}$ has reported a case where he removed, accidentally, between the forceps an enlarged middle lobe of the prostate. In three weeks the patient was reported as recovered, having seldom to micturate more than once in the night.

These illustrations show that two kinds of growth have been removed from the prostate gland in the course of lithotomies, namely, (1) isolated tumours, resembling adenomata,

1 "Observations on Lithotomy and on certain cases of Enlarged Prostate." The 'Lancet,' Jan. 1, 1870.

2 'Trans. Path. Soc.,' vol. xiii.

3 'British Medical Journal,' June 15, 1878. 
the term used by Sir William Fergusson, and (2) ordinary outgrowths or hypertrophies, such as we are most familiar with, as affecting the middle lobe. From the illustrations I have given I submit we may draw three conclusions at the least.

First, that lateral cystotomy may be practised in certain cases of enlarged prostrate which are attended with symptoms producing great distress with the view of exploring and if possible of removing the growth.

Second, that in all cases of cystotomy for calculus where the prostate is found to be enlarged, that a careful search should be made with the finger, with the view of effecting the removal of the growth should such be found practicable.

Third, that in determining the selection of lithotomy or lithotrity in a case where stone in the bladder is complicated with enlargement of the prostate, regard should be had to the possibility of removing both of these causes of distress by the one operation, namely, by lithotomy.

Further, the cases I have recorded seem to indicate the mode in which these growths may best be removed when met with, either in the course of a lithotomy, or a cystotomy performed for the purpose. The presence of isolated growths in the prostate can be ascertained when the gland is opened into, by exploration with the finger; for, as Sir William Fergusson observed, "as the finger passes towards the bladder, the sensation is as if its point glided through several rounded bodies in the substance of the gland, which are but slenderly in contact with each other." Of this sensation I have been conscious in more than one lithotomy I have performed in elderly persons.

Thus discovered these growths may then be enucleated by the finger as I have already endeavoured to demonstrate.

When the growths assume a more pendulous form, as we frequently see when the third lobe is hypertrophied, though they may be detached with the finger or the lithotomy forceps, as occurred in Dr. Williams' case, I 
think a more precise and possibly safer proceeding might be adopted.

I refer, after the bladder has been opened and the growth explored with the finger, to the including of the growth in some simple form of écraseur by which it could be clearly detached without risk of hæmorrhage, just as is sometimes done in the case of a uterine polypus. In referring to such a proceeding, it is with the view of making preparation for what may be necessary when undertaking the operation of lithotomy in a person who is known, or suspected, to have a large prostate, the obstructing portion of which it may be desirable to remove.

In conclusion, I would remark that in none of the cases I have brought forward was the removal of the growth complicated or rendered dangerous by hæmorrhage either at the time of operation or subsequently. 